\title{
Toxic inhalation with hydrogen cyanide prompts a significant increase of mean pulmonal arterial pressure in an animal model
}

\author{
Beelitz J', Kill $\mathrm{C}^{1}$, Feldmann $\mathrm{C}^{2}$, Wulf $\mathrm{H}^{2}$, Vogt $\mathrm{N}^{3}$, Veit $\mathrm{F}^{4}$, Dersch $\mathrm{W}^{2}$
} 'Department of Emergency Medicine, Department of Anaesthesiology and Critical Care, Philipps-University, Marburg, Germany: ${ }^{2}$ Department of Anaesthesiology and Critical Care, Philipps-University, Marburg, Germany; ${ }^{3}$ Department of
Neurosurgery, University of Giessen, Giessen, Germany; ${ }^{4}$ Institute of Legal Medicine, Department of Forensic Toxicology, Justus-Liebig-University Giessen, Giessen, Germany

\section{Objective}

Toxic smoke inhalation contains mainly two major toxic gases carbonmonoxide (CO) and hydrogen cyanide (HCN) leading to hypoxia of cells [1,2]. We investigated the effect of prolonged hydrogen cyanide $(\mathrm{HCN})$ exposure on pulmonal arterial blood pressure during intoxication in a smoke inhalation pig model.

\section{Methods}

With approval by local authorities an intoxication model for pigs $(25-35 \mathrm{~kg})$ with anaesthesia, intubation and instrumentation including a pulmonal arterial catheter was used. Smoke intoxication was simulated by controlled ventilation in a closed circuit with: $t=0 \mathrm{~min}$ (baseline, no toxic gases), $t=5 \mathrm{~min}$ air with $\mathrm{CO}=1500 \mathrm{ppm}$ (parts per million) over 5 minutes, $t=10 \mathrm{~min}$ air with $\mathrm{CO}=750 \mathrm{ppm}$ and $\mathrm{HCN}=500 \mathrm{ppm}$ over 5 minutes, $t=15 \mathrm{~min}$ air with $\mathrm{HCN}=1000 \mathrm{ppm}$. Inhalation was continued until cardiac arrest occurred. The mean pulmonal arteria pressure (mPAP) was recorded from $t=0 \mathrm{~min}$ until $t=30 \mathrm{~min}$. Analysis with Wilcoxon-Test compared to baseline. Results as median (25/75\%percentiles).

\section{Results}

Cardiac arrest occurred in all pigs in a median time of $38 \mathrm{~min}(25.5 / 48.5)$, so that 16 of 24 animals could be included until $t=30 \mathrm{~min}$. $t=0 \mathrm{~min} 21 \mathrm{mmHg}(17 / 23)$, $t=5 \mathrm{~min} 21 \mathrm{mmHg}(19 / 30), p=0.1680 ; t=10 \mathrm{~min} 37 \mathrm{mmHg}(33 / 43), p=<0.0001 ; t=15 \mathrm{~min}$ $36 \mathrm{mmHg}(33 / 41), \quad p=<0.0001 ; t=20 \mathrm{~min} 31 \mathrm{mmHg}(29 / 34), \quad p=0.0003 ; t=25 \mathrm{~min}$ $27 \mathrm{mmHg}(21 / 31), p=0.0259 ; t=30 \mathrm{~min} 22 \mathrm{mmHg}(19 / 25), p=0.3745$.

Mean pulmonal arterial pressure (mPAP) and mean arterial pressure (MAP) during inhalational cyanide intoxication

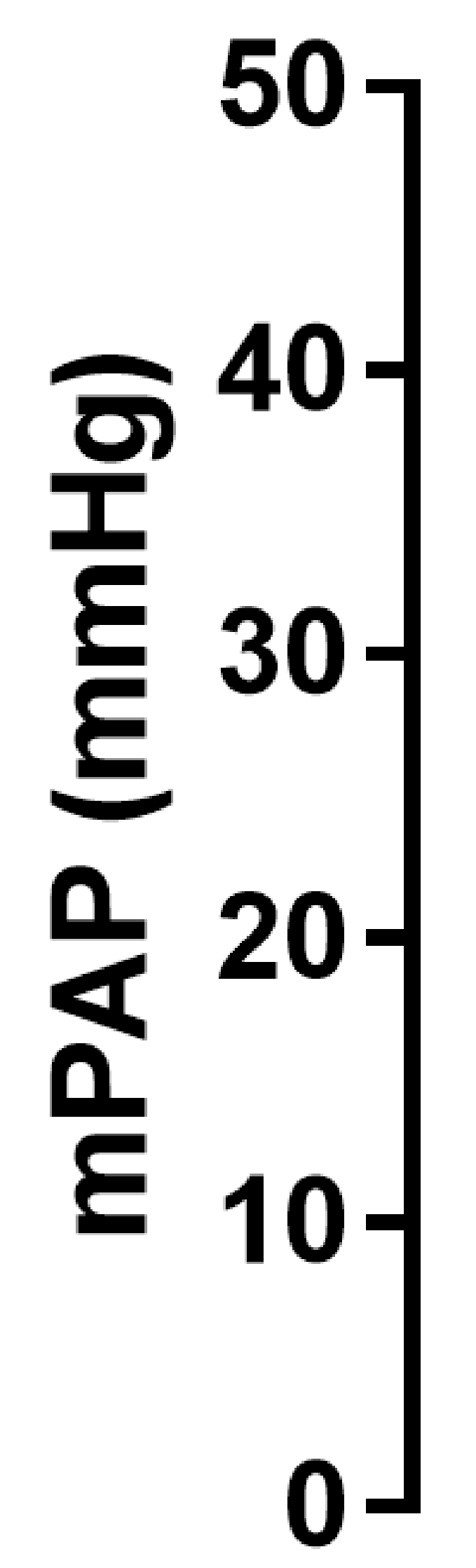

\section{Conclusion}

Hydrogen cyanide inhalation caused an early and significant increase of MPAP. During prolonged intoxication and shortly before cardiac arrest occured mPAP decreased to baseline levels. Further investigations are needed to investigate the effects of hydrogen cyanide on pulmonary vascular tree in detail.

References

[1] Postgrad Med. 1987:82(1):63-8
[2] Crit Rev Toxicol, 2002.32 (4):259-89. 